\title{
Strabismic amblyopia: compliance with occlusion treatment in a tertiary hospital in Midwestern Brazil
}

\author{
Ambliopia estrabísmica: adesão ao tratamento oclusivo \\ em hospital terciário no Centro-Oeste Brasileiro
}

\author{
Márcia Cartaxo Barbosaํำ https://orcid.org/0000-0003-4753-0992 \\ Marcos Pereira de Ávila ${ }^{1}$ https://orcid.org/0000-0002-7752-9549 \\ David Leonardo Cruvinel Isaac ${ }^{1}$ https://orcid.org/0000-0002-0821-2660 \\ Márcio Cartaxo Rebouças ${ }^{2}$ https://orcid.org/0000-0001-7802-633X \\ Lívia Maria Oliveira Salviano ${ }^{1}$ https://orcid.org/0000-0002-4024-5606 \\ João Jorge Nassaralla Neto ${ }^{1}$ https://orcid.org/0000-0002-8274-5051 \\ Crystal Campos Teixeira ${ }^{1}$ https://orcid.org/0000-0001-5034-9989 \\ Rafael Rocha Luzini ${ }^{1}$ https://orcid.org/0000-0002-6129-8141 \\ Caio de Oliveira Trentin ${ }^{1}$ https://orcid.org/0000-0003-3671-5019
}

\begin{abstract}
Purpose: Study aimed to determine compliance of patients with strabismic amblyopia undergoing occlusion treatment, followed from January 1 st, 2011 to January 1 st, 2017 at an Ophthalmology Reference Center, and identify risk factors for poor compliance. Methods: Retrospective, consecutive cohort study. Compliance reported at each visit was related to visual acuity, family history, changes in occlusion schedules and in patients' care team during treatment. The patients were divided into two groups according to the compliance: poor compliance group and compliance group (subdivided in full compliance subgroup and partial compliance subgroup). Results: Age at treatment beginning vary from 3.7 to 13.7 years, esotropia was the most frequent deviation and the occlusion was realized from 5 to 7 hours a day. Of 220 patients, compliance was achieved by 193 (87.7\%), $114(51.8 \%)$ in full compliance subgroup and 79 (35.9\%) in partial compliance subgroup, and 27 do not achieved compliance (12.3\%). Poor compliance was significantly related to a history of epilepsy, higher rate of suspension of treatment due to inefficacy, higher evasion rate, lower recurrence, and lower rate of maintenance of prophylactic occlusion after treatment. Good compliance was related to family history of strabismus, higher recurrence rate, and higher maintenance of prophylactic occlusion after treatment. No relations were found between poor compliance and changes in occlusion schedules or in patients' care team during treatment. Conclusion: Compliance with occlusion treatment of strabismic ambliopia was similar to other studies that included refractive and strabismic amblyopia and not related to changes in occlusion schedules or in patients' care team during treatment. Family history of strabismus was a protective factor.
\end{abstract}

Keywords: Amblyopia; Compliance; Strabismus; Adherence; Binocular vision

\section{RESUMO}

Objetivo: Determinar a adesão de pacientes com ambliopia estrabísmica submetidos a tratamento oclusivo, acompanhados em Centro de Referência em Oftalmologia do Centro-Oeste do Brasil, e identificar fatores de risco para baixa adesão. Métodos: Estudo de coorte retrospectivo e consecutivo. A adesão relatada em cada visita foi relacionada à acuidade visual, história familiar, mudanças no tempo de oclusão e na equipe de atendimento ao paciente durante o tratamento. Os pacientes foram divididos em dois grupos de acordo com a adesão: grupo de não-adesão e grupo adesão (subdividido em subgrupo adesão total e subgrupo adesão parcial). Resultados: A idade ao início do tratamento variou de 3,7 a 13,7 anos, o desvio mais frequente foi a esotropia, o tempo médio de oclusão foi de 5 a 7 horas por dia. Dos 220 pacientes, 193 (87,7\%) obtiveram adesão, 114 (51,8\%) no subgrupo de adesão total e 79 (35,9\%) no subgrupo de adesão parcial, e 27 não aderiram (12,3\%). A não-adesão foi relacionada à história de epilepsia, maior taxa de suspensão do tratamento devido à ineficácia, maior taxa de evasão, menor recorrência e menor taxa de manutenção da oclusão profilática pós tratamento. A boa adesão foi relacionada à história familiar de estrabismo, maior taxa de recorrência e maior manutenção da oclusão profilática pós tratamento. Não houve relação entre não-adesão e mudanças nos horários de oclusão ou na equipe de atendimento durante o tratamento. Conclusão: A adesão ao tratamento oclusivo da ambliopia estrabísmica foi semelhante aos estudos que incluíram ambliopia refracional e estrabísmica e não se correlacionou a mudanças no tempo de oclusão ou na equipe de atendimento. A história familiar de estrabismo foi um fator de proteção.

Descritores: Ambliopia; Distúrbios da visão; Estrabismo; Adesão ao tratamento; Visão binocular

'Centro de Referencia em Oftalmologia, Goiânia, GO, Brazil.

${ }^{2}$ Academic Course, Centro Universitário de Mineiros, Mineiros, GO, Brazil.

Instituição/Afiliação: Centro de Referencia em Oftalmologia, Goiânia, GO, Brazil.

The authors declare no conflict of interest

Received for publication 6/3/2020 - Accepted for publication 19/8/2020. 


\section{INTRODUCTION}

A mblyopia is a neurological disorder of vision affecting one or both eyes due to impaired development during the visual plasticity period. Among several possible causes of amblyopia, strabismus is the most frequent one. ${ }^{(1)}$ The treatment of amblyopia should start before the age of 12 years, although it may still improve visual acuity in patients up to 17 years old not previously treated. (2) Occlusion of the best eye (fellow eye) with an opaque patch is still the gold standard treatment for amblyopia in order to stimulate the amblyopic eye. ${ }^{(3)}$ The effectiveness of this treatment is influenced by factors such as compliance, length of treatment, and therapeutic regimens. ${ }^{(4)}$

This study aimed to evaluate compliance with occlusion treatment (patching) and the related factors in a population treated for strabismic amblyopia in a tertiary hospital in Midwestern, in Goiânia, GO, Brazil, from January 1st, 2011 to January 1st, 2017.

\section{MethodS}

This retrospective, consecutive cohort study was carried out based on medical records of the hospital outpatients treated by ophthalmologists and residents in ophthalmology for amblyopia from January 1st, 2011 to January 1st, 2017. Occlusion was prescribed as prophylactic or therapeutic treatment. The prophylactic treatment was performed in non-amblyopic patients at risk of developing the disorder, i.e. with strabismus, anisometropia, infantile cataract, or ptosis, one day in each eye, increasing the number of patching hours per day according to the age. In the therapeutic treatment, recommended for amblyopic patients, patching prescription was different for each eye, occluding the fellow eye for more consecutive days according to the degree of amblyopia. In the routine of the institution, number of hours of occlusion was dictated by both age and severity of amblyopia, starting with $2 \mathrm{~h}$ of daily patching and increasing the dosage with age and severity up to $12 \mathrm{~h}$ per day.

In the patients selected to this study, specifically, it was performed in media 6 hours a day in those with visual acuity better than 20/40 (0.2 logMar or better), 7 hours a day in those with visual acuity between 20/40 and 20/100 (0.3 and $0.7 \log M a r)$, and 8 hours in those with visual acuity worse than 20/100 (0,8 logMar or worse). The amblyopic eye was occluded for at least one day per week during the treatment to avoid reverse amblyopia ${ }^{(5)}$ and the fellow eye was occluded in media 3 days in patients aged less than 4 years, 6 days in those between 4 and 7 years and 5 days in those above 7 years.

Inclusion criteria were: a. amblyopia: defined as the difference of two lines between the best corrected visual acuity of both eyes in verbal children; ${ }^{(6)}$ b. strabismus: defined as a deviation from binocular alignment ${ }^{(7)}$ and classified as esotropia, exotropia, hyper or hypotropia, esotropia with hyper or hypotropia, exotropia with hyper or hypotropia; ${ }^{(8)}$ c. occlusion treatment: skin patch. ${ }^{(5)}$

Exclusion criteria were: a. organic low vision, defined as media opacities or fundoscopic changes ${ }^{(6)} b$. treatment not concluded at the end of the research period; c. incomplete or illegible description in the medical record; d. non-verbal children.

Follow-up visits were programmed on a case-by-case basis according to the age of the patient and severity of amblyopia. Corrected visual acuity of each eye and compliance reported by parents or legal guardians were evaluated at each follow-up visit, and results were measured by patient, not by eye. ${ }^{(9)}$ The variables evaluated were: age (day/month/year of birth); date of each appointment from the beginning of the occlusion treatment until the last follow-up visit (day/month/year); gender (male/ female); origin (Goiânia/city in the interior of the state of Goiás/ other parts of Brazil); past medical history of patients; ametropia according to the Brazilian Council of Ophthalmology; ${ }^{(10)}$ occlusion treatment (every follow-up visit); visual acuity: best corrected visual acuity at the beginning of treatment, at 6 months, and at the end of treatment. Visual acuity variation during treatment was classified as: improved (got better at least one line), stable (did not change), or worse (got worse at least one line despite the treatment).Visual acuity was measured in a 6-meter Snellen chart with clustered optotypes without correction and with correction in the first return after cycloplegia induced by $1 \%$ cyclopentolate and $1 \%$ tropicamide. Refraction prescription followed the parameters of the Brazilian Society of Pediatric Ophthalmology. (11) The results were converted into logMar for the statistics analyses; ${ }^{(9,12,13)}$ compliance reported by parents or legal guardians (14) was classified into three groups: less than 30 min of occlusion, doses reaching $30 \%$ to $80 \%$ off the prescribed period, and doses reaching about $100 \%$ off prescription, ${ }^{(13)}$ the first one was named poor compliance group (PCG) and the sum of the last two ones was called compliance group (CG); the two parts of CG were named partial compliance subgroup (PCS) and full compliance subgroup (FCS), respectively; end of treatment was achieved when visual acuity ceased to improve in three consecutive follow-up visits, and it was classified as completion of treatment (patient improved visual acuity during treatment), suspension of treatment due to inefficacy (no improvement achieved), or evasion (patient missed follow-up visits).

Reproducibility studies showed that only a change in visual acuity of $0.2 \log$ Mar or more can be considered real. ${ }^{(15)}$ Therefore, the visual acuity changes were calculated according to this criterion. Residual amblyopia, i.e. the difference between the final visual acuity of the fellow eye and that of the amblyopic eye, and the proportional improvement, i.e. the percentage of improvement in the amblyopic eye compared to the dominant eye, taking into account that the visual acuity of the latter corresponds to $100 \%$, were calculated. Residual amblyopia of $0.0 \log$ Mar and proportional improvement of $100 \%$ represent the best possible outcome of occlusion treatments ${ }^{\left({ }^{(}\right)}$. Amblyopia severity was also evaluated, considering moderate amblyopia the corrected visual acuity of the worst eye between 20/40 and 20/100, mild amblyopia above $20 / 40$, and severe amblyopia below 20/100. ${ }^{(6)}$

The minimum sample size required for this study was 220 patients with strabismic amblyopia who underwent occlusion treatment, calculated with a sampling error of $6,48 \%$, at a $95 \%$ confidence interval, and significance at $\mathrm{p}<0.05$. $^{(14-16)}$

Variables presented as means of PCG and CG were compared using the Student's t-test for independent data, whereas those of PCG and subgroups were compared using the one-way analysis of variance (ANOVA). Variables presented in absolute numbers in PCG and CG were compared using the Mann-Whitney $\mathrm{U}$ test, while those in PCG and subgroups were compared using the Chi-square test (or the Kruskal-Wallis test if any group had less than five patients in the comparison).

Data analysis was performed using the Statistical Package for Social Sciences (SPSS) for Windows version 21.0 (IBM Corp., Armonk, NY, USA), and statistical significance was set at $\mathrm{p}<0.05$.

This study was performed according to the principles of the Declaration of Helsinki (1964), and all national, state, and local laws or regulations. The research was approved by the Ethics Com- 


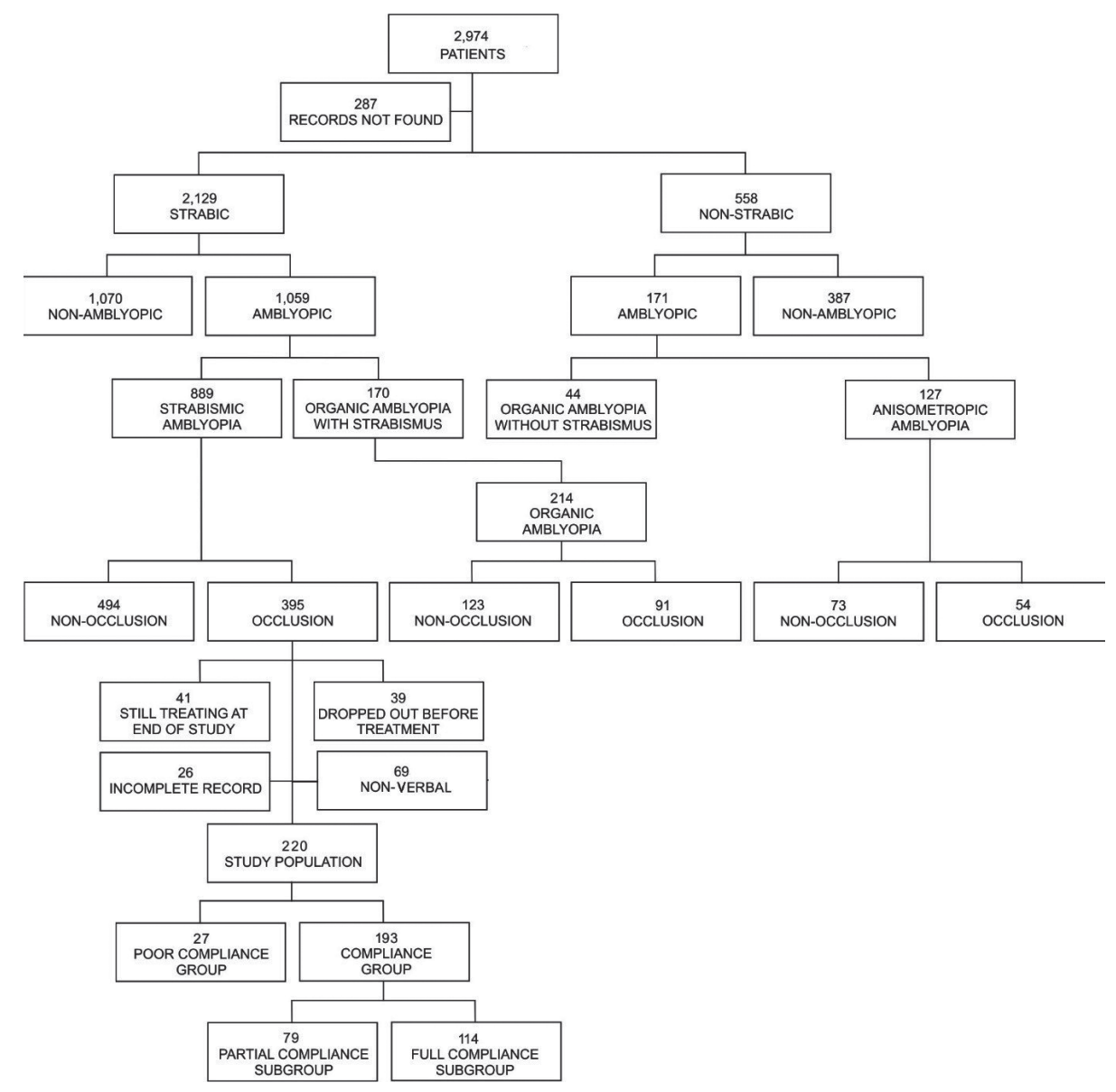

Figure 1: Study population sampling.

mittee in Human and Animal Medical Research of the Clinical Hospital of the Federal University of Goiás (Protocol no. 98/2016).

\section{RESULTS}

Of the 2,974 outpatients treated from January 1th, 2011 to January 1th, 2017,220 met the inclusion criteria and were selected. The sample was divided into two groups: PCG $(\mathrm{n}=27)$ and CG (n $=193)$. CG was subdivided into PCS $(\mathrm{n}=79)$ and FCS $(\mathrm{n}=114)$ for statistical analyses (Figure 1).

The sociodemographic profile and baseline characteristics of the patients included in the study are shown in table 1 . After prescription of occlusion treatment, $51,8 \%$ of the patients achieved full compliance, $35,9 \%$ showed partial compliance, and $12,3 \%$ were in PCG. Women were $42.3 \%(p=0.66)$, the mean age at the beginning of the treatment was 6.6 years $(p=0.12), 62.9 \%$ of the participants lived in Goiânia, and the most frequent deviation was esotropia $(61.8 \%)$.

The age at the start of treatment vary from 3.7 to 13.75 years. The mean age at end of the treatment was the only statistically significant variable $(\mathrm{p}=0.04)$ : 9.11, 8.42, 7.81, and 8.13 years in PCG, CG, PCS, and FCS, respectively. Comparison between groups showed significance between PCG and CG $(\mathrm{p}=0.03)$, as well as between PCG and FCS ( $p=0.04)$. It means that Poor Compliance Group has a higher mean age at the end of treatment.

Left eyes were more frequently affected by amblyopia in all the groups $(\mathrm{n}=122)$, and no statistical differences were observed between them. The mean refractions were $+2.14-0.5570^{\circ}$ in the right eye and $+2.17-0.8052^{\circ}$ in the left eye, with no statistical significance between groups.

The past medical history of the participants is shown in table 2. Strabismus surgery refer to these treatments during the period of patching. Patients accompanied by others were taken to the appointments by a legal guardian other than the father or mother. Statistical significance was found for epilepsy comparing PCG and CG ( $p=0.01)$, and for epilepsy comparing PCG and the subgroups $(\mathrm{p}=0.03)$.

Figure 2 shows the rates of evasion, suspension of treatment due to inefficacy, recurrence, and post-treatment maintenance in the study population, groups, and subgroups. Post-treatment maintenance refers to keeping prophylactic patching of each eye at least one day per week after cessation of amblyopia treatment to reduce the risk of recurrence. ${ }^{(5)}$ This rate was significantly higher in CG compared to PCG $(\mathrm{p}=0.00)$ and also in PCG compared to the subgroups $(\mathrm{p}=0.00)$.

The mean duration of treatment was 2 years for the patients in PCG and 2.1 years in CG $(\mathrm{p}=0.66)$. The frequency of follow-up was 2.86 years in PCG and 3.62 years in $C G(p=0.13)$.

During the amblyopia treatment, 78 patients required changes in patching schedule $(\mathrm{n}=8$ in PCG; $\mathrm{n}=36$ in PCS; $\mathrm{n}=$ 34 in FCS), increasing or reducing hours or increasing or reducing days of occlusion, but no statistically significant difference was 
Table 1

Sociodemographic profile and baseline characteristics of 220 participants presenting with strabismic amblyopia treated with occlusion

\begin{tabular}{|c|c|c|c|c|c|c|c|}
\hline Variable & Total & PCG & PCS & FCS & $\mathbf{C G}$ & $\begin{array}{r}\text { PCG x subgroups } \\
\text { p value }\end{array}$ & PCG x CG \\
\hline Total population, $\mathrm{n}$ & 220 & 27 & 79 & 114 & 193 & & \\
\hline Mean age at beginning, yrs & 6.6 & 7.4 & 6.1 & 6.4 & 6.2 & 0.12 & \\
\hline Mean age at end, yrs & 8.4 & 9.1 & 8.4 & 7.8 & 8.1 & $0.04 *$ & $0.03 *$ \\
\hline Female, $\mathrm{n}$ & 94 & 9 & 38 & 47 & 85 & 0.66 & \\
\hline Male, $\mathrm{n}$ & 129 & 18 & 41 & 67 & 108 & & \\
\hline From other states in Brazil, $\mathrm{n}$ & 1 & 0 & 0 & 1 & 1 & & \\
\hline Esotropia (et), n & 137 & 18 & 49 & 70 & 119 & 0.62 & \\
\hline Exotropia (xt), n & 32 & 3 & 14 & 15 & 29 & & \\
\hline Hypo/hypertropia(ht), n & 2 & 0 & 1 & 1 & 2 & & \\
\hline $\mathrm{et}+\mathrm{ht}, \mathrm{n}$ & 39 & 4 & 12 & 23 & 35 & & \\
\hline $\mathrm{xt}+\mathrm{ht}, \mathrm{n}$ & 10 & 2 & 4 & 4 & 8 & & \\
\hline
\end{tabular}

PCG = poor compliance group; $\mathrm{PCS}$ = partial compliance subgroup FCS = full compliance subgroup; $\mathrm{CG}=$ compliance group.

Statistically significant difference between groups $(\mathrm{p}<0.05)$. Frequencies followed by the asterisk $(*)$ differ statistically by the Student's t-test for independent data (PCG x CG) or ANOVA (PCG x FCS x PCS) in case of variables presented as means. Variables presented in absolute numbers in PCG and CG were compared using the Mann-Whitney U test, while those in PCG and subgroups were compared using the Chi-square test (or Kruskal-Wallis test if any group had less than five patients).

Table 2

Past medical history of 220 participants presenting with strabismic amblyopia treated with occlusion

\begin{tabular}{|c|c|c|c|c|c|c|c|}
\hline Variable & Total & PCG & PCS & FCS & CG & $\begin{array}{r}\text { PCG x subgroups } \\
\text { p value }\end{array}$ & PCG x CG \\
\hline Pre-treatment occlusion, $\mathrm{n}$ & 64 & 6 & 24 & 34 & 58 & 0.18 & 0.66 \\
\hline Previous amblyopia treatment, $\mathrm{n}$ & 31 & 7 & 11 & 13 & 24 & 0.20 & 0.11 \\
\hline Neurological delay, $\mathrm{n}$ & 17 & 0 & 4 & 7 & 11 & 0.28 & 0.12 \\
\hline Prematurity, $\mathrm{n}$ & 9 & 1 & 4 & 4 & 8 & 0.87 & 0.60 \\
\hline Strabismus surgery, $\mathrm{n}$ & 11 & 1 & 5 & 5 & 10 & 0.80 & 0.65 \\
\hline \multicolumn{8}{|l|}{ Mother with } \\
\hline Toxoplasmosis, $\mathrm{n}$ & 1 & 0 & 0 & 1 & 1 & 0.61 & 0.71 \\
\hline Amblyopia in the family, $\mathrm{n}$ & 1 & 0 & 0 & 1 & 1 & 0.61 & 0.71 \\
\hline Twinning, $\mathrm{n}$ & 1 & 0 & 0 & 1 & 1 & 0.61 & 0.71 \\
\hline Epilepsy, n & 1 & 1 & 0 & 0 & 0 & $0.03 *$ & $0.01 *$ \\
\hline
\end{tabular}

$\mathrm{PCG}=$ poor compliance group PCS = partial compliance subgroup; $\mathrm{FCS}=$ full compliance subgroup $\mathrm{CG}=$ compliance group.

Statistically significant difference between groups $(\mathrm{p}<0.05)$. Frequencies followed by the asterisk $(*)$ differ statistically by the Mann-Whitney $U$ test (PCG x CG), while those in PCG and subgroups were compared using the Chi-square test (or Kruskal-Wallis test if any group had less than five patients)

Table 3

Amblyopia classification per group at beginning, 6 months and end of occlusive treatment of the study population

\begin{tabular}{lccccccc}
\hline Amblyopia classification & start & $\begin{array}{c}\text { Mild } \\
\text { 6 months }\end{array}$ & end & start & $\begin{array}{c}\text { Moderate } \\
\text { 6 months }\end{array}$ & $\begin{array}{c}\text { Severe } \\
\text { end }\end{array}$ & $\begin{array}{c}\text { start } \\
\text { 6 months }\end{array}$ \\
\hline end
\end{tabular}

Amblyopia classification regards visual acuity: mild amblyopia - visual acuity better than 20/40 (0.2 logMar or better), moderate amblyopia - visual acuity between 20/40 and 20/100 (0.3 and 0.7 logMar), and severe amblyopia - visual acuity worse than 20/100 (0,8 logMar or worse). Start refers to beginning of occlusive treatment, 6 months refers to 6 months of treatment and end refers to treatmens end 


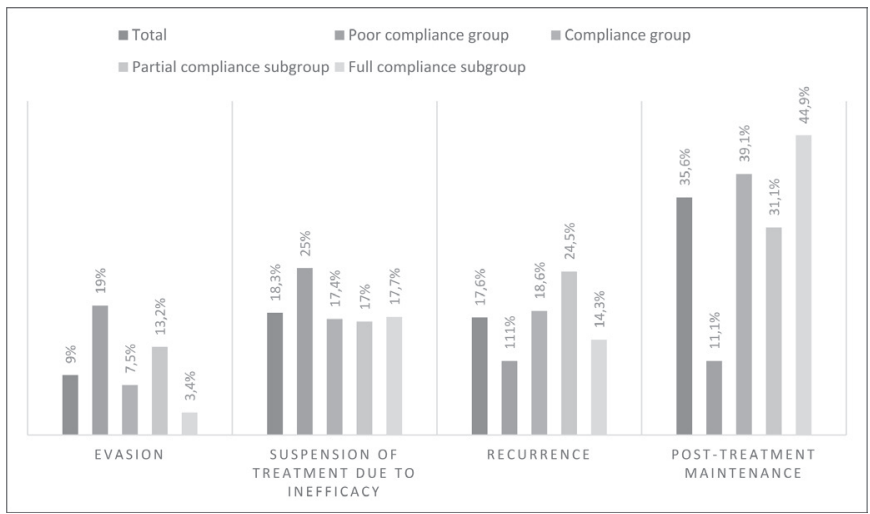

Figure 2: Evasion, suspension of treatment due to inefficacy, recurrence, and post-treatment maintenance rates of the study population.

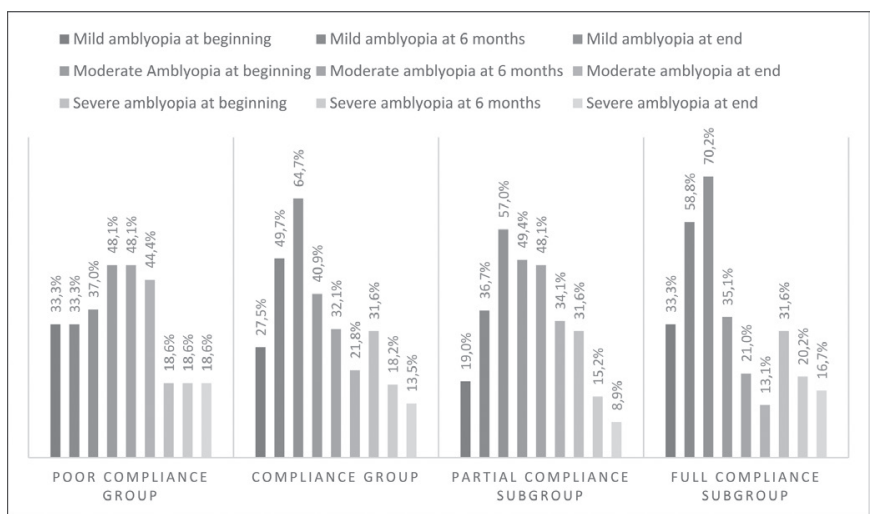

Figure 3: Amblyopia classification perceptual rates of the study population per group.

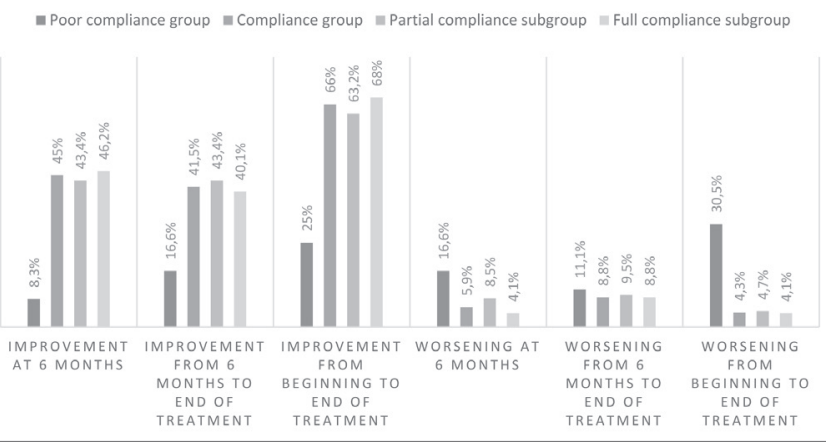

Figure 4: Amblyopic-eye acuity improvement and worsening for each study group at the beginning of treatment, at 6 months, and at the end of treatment.

found between groups $(\mathrm{p}=0.32)$. The most frequent changes in patching schedule were increased number of days of right eye occlusion $(34.7 \%)$ and increased number of days of left eye occlusion $(14.8 \%)$.

Although 52 patients experienced changes in patients' care team during treatment ( $\mathrm{n}=9$ in PCG; $\mathrm{n}=18$ in PCS; $\mathrm{n}=25$ in FCS), their compliance was similar to that achieved by those that had the same team until the end of the follow-up period $(p=0.24)$.

Visual acuity was measured in each return and it was used to determine the depth of amblyopia in each group, as described in table 3 , at the beginning, at 6 months and at the end of treatment. It also allows to determine the perceptual of patients in each group classified as mild, moderate and severe amblyopia at the beginning, at 6 months and at the end of treatment, as show in figure 3 .

The visual acuity values of amblyopic eye at beginning, 6 months and end allow to classify the patients in improvement or worsening, if they had better visual acuity during the study period or worse. Figure 4 shows the percentages of amblyopic-eye acuity improvement and worsening for each study group at 6 months and at the end of treatment. A statistically significant difference was found for visual acuity improvement at 6 months and at the end of treatment comparing PCG to all the other groups $(\mathrm{p}=0.00)$.

Worsening of amblyopic eye visual acuity was significantly different in PCG compared to CG and FCS at the end of treatment $(\mathrm{p}=0.00)$. Amblyopia at the beginning of treatment was moderate in $75(42.1 \%)$ of the patients, mild in $62(29.1 \%)$, and severe in 66 (28.7\%). No significant difference was observed between groups regarding severity of amblyopia. The improvement of $0.2 \log$ Mar or more in visual acuity was lower in PCG compared to all the other groups from the beginning to the end of treatment $(p=0.01$ compared to $\mathrm{CG} ; \mathrm{p}=0.047$ compared to subgroups).

The visual acuity values also permitted to calculate residual amblyopia, by difference between the final visual acuity of the fellow eye and that of the amblyopic eye, and the proportional improvement, by the percentage of improvement in the amblyopic eye compared to the dominant eye, taking into account that the visual acuity of the latter corresponds to $100 \%$. $^{(6)}$ Significant improvement was achieved comparing PCG and CG $(p=0.00)$, as well as PCG and FCS $(p=0.00)$ for patients that reached the end of the treatment with similar visual acuity in the previously amblyopic eye and in the fellow eye, achieving zero residual amblyopia and a $100 \%$ improvement. In PCG two patients reached this improvement compared to 121 in CG ( $\mathrm{n}=42$ in PCS; $\mathrm{n}=79$ in FCS). It means that 123 patients end the treatment with equal visual acuity in both eyes.

The mean residual amblyopia for each group was higher in PCG compared to all the other groups $(\mathrm{p}=0.01$ compared to the subgroups; $\mathrm{p}=0.02$ compared to $\mathrm{CG}$ ). The mean proportional improvement was statistically significant comparing PCG to CG and to FCS ( $\mathrm{p}=0.00$ and $\mathrm{p}=0.01$, respectively), but not compared to PCS $(\mathrm{p}=0.22)$.

\section{Discussion}

In the present study, compliance was $87.7 \%$, with $51.8 \%$ of the patients achieving full compliance. These rates are higher than those found in other studies $(33-73.5 \%),{ }^{(6,9,16,17)}$ and close to the result reported by Arakaki at al. ${ }^{(17)}(73.5 \%)$. This variation may be partially explained by the diversity of methods used for assessing what is considered compliance.

The division of this study group was based on Wallace et al. ${ }^{(9)}$ and they reported a $44 \%$ compliance rate with electronically monitored occlusion therapy. Considering that Stewart et al. ${ }^{(14)}$ found out that electronically monitored compliance was half of the reported compliance, in their study the reported compliance would be $88 \%$, compatible with our findings.

Another important relation between electronically monitored and reported compliance is that some patients of PCS in our study could actually be part of PCG and cause a bias. In FCS it could not occur, because the lowest compliance rate was $80 \%$. Therefore, monitored compliance would be at least $40 \%$ in FCS and these patients would still be considered compliant. To avoid this possibility of bias, we performed statistical analysis per subgroup. 
History of epilepsy were related to compliance and remained statistically significant comparing PCG and FCS $(\mathrm{p}=0.01)$.

Evasion rate was $9 \%$ and suspension of treatment due to inefficacy was $18.3 \%$, both directly related to poor compliance ( $\mathrm{p}$ $=0.00$ for both). Recurrence rate was $17.6 \%$ and it was higher in CG. This result is above the recurrence rates observed by Holmes at al. ${ }^{(4)}: 14 \%$ for patients that progressively reduced the occlusion treatment and $42 \%$ for those that abruptly stopped the treatment.

Maintenance of prophylactic patching after the end of treatment was significantly higher in CG compared to PCG ( $\mathrm{p}=$ 0.001). In this study, no positive relationship was found between a lower frequency of review assessments as described by Wallace et al. ${ }^{(9)}$ The mean treatment period was 2 years, similar to that reported by Gonçalves et al. ${ }^{(18)}$

The possible correlations between compliance and patients' care team were evaluated taking into account changes in number of patching hours or days and changes in patients' care team during treatment. To the best of our knowledge, this is the first study seeking for possible correlations between compliance and patients' care team. Neither changes in patients' care team ( $\mathrm{p}=$ 0.24 ) nor changes in number of patching hours or days, either decreasing or increasing the number of days or hours $(p=0.32)$, affected compliance.

Improvements in visual acuity were significantly lower in PCG compared to all the other groups and remained after 6 months, which is compatible with other results ${ }^{(6)}$, despite the differences in occlusion schedules. Worsening of amblyopic eye visual acuity was significant only comparing PCG to FCS. A possible explanation is the bias of reported compliance described before, which could have made PCS and PCG more homogeneous.

An average improvement of $0.33 \log$ Mar was observed in $\mathrm{CG}$, and an even higher improvement occurred in FCS $(0.35$ $\log$ Mar). These improvements are similar to that of MOTAS ${ }^{(6)}$ (0.35 logMar).

As suggested by Stewart at al. [16], we also measured a change in visual acuity of $0.2 \log$ Mar or more in the analysis of visual acuity improvement. And this change was significant comparing PCG to all the other groups in the interval from the beginning to the end of the treatment in the present study.

Residual amblyopia and the proportional improvement were calculated ${ }^{(6)}$, and a significant improvement was found comparing patients who achieved zero residual amblyopia and a $100 \%$ improvement in PCG and those in CG $(\mathrm{p}=0.00)$.

The initial mean age was 6.6 years and the final mean age was 8.4 years, similar to the age bands studied by other authors. ${ }^{(1,15)}$ Age at the end of treatment was significantly higher in PCG as demonstrate in Table 1 (9.1 years; $p=0.04)$. The same was found by Wallace et al. ${ }^{(9)}$ in a European population and demonstrates that the treatment can be prolonged due to lack of compliance.

Esotropia was more frequent in the study population than in other ones. ${ }^{(8,18,19)}$ Few studies have been conducted to evaluate compliance with occlusion treatment for amblyopia in Brazil. Even in studies that evaluated compliance in other populations around the world, amblyopia cases included strabismus, anisometropia, and mixed amblyopia. ${ }^{(9,20)}$ This fact could create a bias, because they are grouping together amblyopia cases of different etiologies, which could interfere in the treatment. In patients with anisometropia, the cause of amblyopia is treated with glasses before the use of occlusive therapy. In contrast, strabismus is not treated before occlusion in patients with strabismic amblyopia. Therefore, in cases of strabismic amblyopia, the amblyopia mechanism is still there during patching and grouping it with aniso- metropia could generate unreliable results. This study presented a differential for analyzing only cases of strabismic amblyopia.

\section{CONCLUSION}

In conclusion, poor compliance was significantly related to a higher mean age at the end of treatment, higher evasion rate, higher rate of suspension of treatment due to inefficacy, lower recurrence, and lower rate of maintenance of prophylactic occlusion after treatment. The following variables did not interfere with compliance: age at the beginning of treatment, frequency of follow-up visits, origin, prophylactic occlusion prior to treatment, changes in patients' care team during occlusion treatment, changes in number of patching hours or days (occlusion schedules), or being accompanied by parents or legal guardians in follow-up visits.

\section{ReFERENCES}

1. Díaz PJ, Sousa-Dias CR. Estrabismo. 4a ed. São Paulo: Livraria Santos; 2002.

2. Scheiman MM, Hertle RW, Beck RW, Edwards AR, Birch E, Cotter SA, et al.; Pediatric Eye Disease Investigator Group. Randomized trial of treatment of amblyopia in children aged 7 to 17 years. Arch Ophthalmol. 2005;123(4):437-47.

3. Vasconcelos GC, Costa MF. Tratamento atual da ambliopia: onde estamos? [editorial]. Arq Bras Oftalmol. 2013;76(4):VII-VIII.

4. Holmes JM, Beck RW, Kraker RT, Astle WF, Birch EE, Cole SR, et al.; Pediatric Eye Disease Investigator Group. Risk of amblyopia recurrence after cessation of treatment. J AAPOS. 2004;8(5):420-8.

5. Bicas HE. Visão binocular. Estrabismos. Medicina (B Aires). 1997;30(1):27-35.

6. Stewart CE, Moseley MJ, Stephens DA, Fielder AR. Treatment dose-response in amblyopia therapy: the Monitored Occlusion Treatment of Amblyopia Study (MOTAS). lnvest Ophthalmol Vis Sci. 2004;45(9):3048-54.

7. Spalton DJ,Hitchings RA, Hunter PA. Atlas de oftalmologia clínica. 3a ed. Rio de Janeiro. Elsevier; 2006.

8. Kac MJ, Freitas Júnior MB, Kac SI, Andrade EP. Freqüência dos tipos de desvios oculares no ambulatório de motilidade ocular extrínseca do Hospital do Servidor Público Estadual de São Paulo. Arq Bras Oftalmol. 2007;70(6):939-42.

9. Wallace MP, Stewart CE, Moseley MJ, Stephens DA, Fielder AR; Monitored Occlusion Treatment Amblyopia Study (MOTAS) Cooperatives; Randomized Occlusion Treatment Amblyopia Study (ROTAS) Cooperatives. Compliance with occlusion therapy for childhood amblyopia. Invest Ophthalmol Vis Sci. 2013;54(9):6158-66.

10. Conselho Brasileiro de Oftalmologia. Manual de ajuste de condutas. 6a ed. São Paulo: Walprint Gráfica e Editora; 2012

11. Tartarella MB, Ferreira RC, Verçosa IM, Fortes Filho JB. (2016) Recomendações sobre refração em crianças pré-verbais. e-Oftalmo. [citado 2018 Aug 26].2 Disponível em: http://200.98.68.239/eoftalmo/ Content/imagebank/pdf/v2n3a03.pdf

12. Messias A, Jorge R, Cruz AA. Tabelas para medir acuidade visual com escala logarítmica: porque usar e como construir. Arq Bras Oftalmol. 2010;73(1):100.

13. de Zárate BR, Tejedor J. Current concepts in the management of amblyopia. Clin Ophthalmol. 2007;1(4):403-14.

14. Stewart CE, Stephens DA, Fielder AR, Moseley MJ; ROTAS Cooperative. Objectively monitored patching regimens for treatment of amblyopia: randomised trial. BMJ. 2007;335(7622):707. 
15. Costa DS, Klein RC, Leite CA, Ginguerra MA, Polati M. Ambliopia por estrabismo: estudo retrospectivo de pacientes em hospital universitário. Arq Bras Oftalmol. 2006;69(2):181-5.

16. Stewart CE, Fielder AR, Stephens DA, Moseley MJ. Design of the Monitored Occlusion Treatment of Amblyopia Study (MOTAS). Br J Ophthalmol. 2002;86(8):915-9.

17. Arakaki MR, Schellini AS, Heimbeck FJ, Furuya MT, Padovani CR. Adesão ao tratamento da ambliopia. Arq Bras Oftalmol. 2004;67(2):201-5.

18. Gonçalves F, Schellini SA, Heimbeck FJ, Furuya MT, Padovani CR. Causas de ambliopia e resultados do tratamento. Rev Bras Oftalmol. 2006;65(2):104-8.
19. Rocha MN, Sanches A, Pessoa FF, Braz GS, Rego LP, Auad LJ, et al. Clinical forms and risk factors associated with strabismus in visual binocularity. Rev Bras Oftalmol. 2016;75(1):34-9.

20. Pediatric Eye Disease Investigator Group. A randomized trial of atropine vs. patching for treatment of moderate amblyopia in children. Arch Ophthalmol. 2002;120(3):268-78.

Corresponding Author:

Márcia Cartaxo Barbosa

mcartaxobarbosa@gmail.com 